\title{
Differential vineyard fertilizer management based on nutrient's spatio-temporal variability
}

\author{
João Serrano $^{1 *}$, J. Marques da Silva ${ }^{1}$, S. Shahidian ${ }^{1}$, L.L. Silva ${ }^{1}$, A. Sousa ${ }^{1}$ and F. Baptista ${ }^{1}$
}

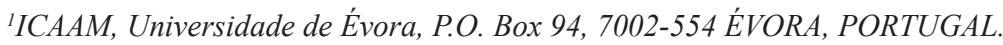

Correspondingauthor:jmrs@uevora.pt

\begin{abstract}
Conventionally, vineyard fertilizer management has been based on information from composite soil samples and no account has been taken of the existing spatial variability in soil fertility. This study presents a quantitative analysis of soil phosphorus $\left(\mathrm{P}_{2} \mathrm{O}_{5}\right)$ and potassium $\left(\mathrm{K}_{2} \mathrm{O}\right)$ content as well as $\mathrm{pH}$ carried out in an 80 ha vineyard, during 2011 and 2013 in order to identify their spatial variability and temporal stability. Additionally a quantitative analysis of plant $\mathrm{P}_{2} \mathrm{O}_{5}$ and $\mathrm{K}_{2} \mathrm{O}$ content was carried out in 2013 with the objective of evaluating the spatial variability of plant nutrients. In 2013 a contact sensor was used to survey soil apparent electrical conductivity $\left(\mathrm{EC}_{\mathrm{a}}\right)$ and an active optical sensor was used to measure the plant Normalized Difference Vegetation Index (NDVI). The results showed a low potential for implementing site-specific management of phosphorus fertilizer but an interesting potential for implementing site-specific management of potassium fertilizer and $\mathrm{pH}$ correction. The concentration of $\mathrm{P}_{2} \mathrm{O}_{5}$ and $\mathrm{K}_{2} \mathrm{O}$ in the plant showed a $\mathrm{CV}<30 \%$, with adequate values in almost the entire area of the field, in contrast to the concentration of these main macronutrients in the topsoil. These results show that for differential nutrient management of vineyards, plant nutrient concentration is a more stable tool than soil nutrients concentration. The $\mathrm{EC}_{\mathrm{a}}$ and the NDVI presented weak correlations with soil and plant concentration of, , respectively, $\mathrm{P}_{2} \mathrm{O}_{5}$ and $\mathrm{K}_{2} \mathrm{O}$, which shows that further development of vegetation operational sensors is needed to support decision making in the vineyard fertilization management.
\end{abstract}

Keywords: Fertilizer management, vineyard, spatial variability, plant nutrition, NDVI, apparent soil electrical conductivity 


\section{Introduction}

A sustainable agricultural soil-plant system is necessary to guarantee both the production of healthy foods and preservation of the environmental. To achieve these aims it is fundamental to promote plant performance and soil health, properties which are a result of the interactions between chemical, physical and biological factors known as the "macro-components of soil fertility" (Azcón-Aguilar and Barea, 2015).

The main aim of modern oenology is to produce wines of recognized quality and typicity, which can then be differentiated in an ever more demanding market. Soil properties, together with climate, directly affect vine development, berry composition and wine quality potential (Stevanato et al., 2014). Considering that spatial variability is one of the major soil characteristics, variation in soil properties appears to be a key driver of vineyard yield and quality variability (Unamunzaga et al., 2014). Viticulture is always intensively managed, with high agrochemical inputs, including fertilizers. Nevertheless, conventional fertilizer management of vines is based on composite soil samples which do not take account of the spatial variability in soil fertility. Detailed knowledge about spatial variability of soil chemical and physical properties is essential for modern viticulture management (Rodríguez-Pérez, 2011; Unamunzaga et al., 2014).

The decision by farmers to adopt differentiated fertilization strategies within a field is usually supported by maps of soil spatial variability and temporal stability, using techniques described by various authors (Shi et al., 2002; Xu et al., 2006; Serrano et al., 2014). This method combines both spatial and temporal effects into a single map of management classes. A combination of soil sampling at discrete locations and geostatistics is widely used to provide soil spatial information (Corwin and Lesch, 2005), however, this method is expensive and time-consuming due to the fact that it demands intensive sampling in order to attain a good representation of the soil properties (Morari et al., 2009), which is not viable for site-specific vineyard management (Corwin and Lesch, 2005; Morari et al., 2009; Peralta and Costa, 2013).

Another possible method of vineyard nutrition management and optimization is chemical analysis of nutrient concentration in leaves and petioles. The studies of Robinson et al., (1997) and Goldspink and Howes (2001), for example, are guidelines for interpreting the results of the petiole analysis in the vineyard. However, this approach is also rather expensive and, normally, performed with low spatial resolution (Homolová et al., 2013).

For these reasons, vine nutrition management and optimization are rather complex, which is aggravated by the fact that vine roots can expand to great soil depths and, consequently, the correlation between plant and soil nutrient concentrations is usually very low. Crop management currently tends to promote the use of efficient and inexpensive methods over larger areas to acquire information on crop parameters, decisive for sustainable management. With the current availability of expedite equipment for soil and crop monitoring, associated with location and geographic information systems (GIS) it is possible to measure, estimate and manage within-field variability, crucial for precision viticulture (Morari et al., 2009).

The application of geospatial measurements of apparent soil electrical conductivity $\left(\mathrm{EC}_{\mathrm{a}}\right)$ is a practical and efficient technique to quickly characterize the spatial high-resolution pattern of soil properties within fields and a less expensive alternative to manual gathering of soil quality indicators (Corwin and Lesch, 2005; Moral et al., 2010; Peralta and Costa, 2013; Doolittle and Brevik, 2014). Especially, the measurements of $\mathrm{EC}_{\mathrm{a}}$ have a great potential for optimizing soil sampling 
to better characterize the spatial pattern of edaphic properties influencing crop yield, which in turn can be used to define site-specific management units (Moral et al., 2010). Nevertheless, this technique does have some limitations: results are site-specific and the correlations depend on complex interactions between soil variables (Peralta and Costa, 2013; Doolittle and Brevik, 2014).

On the other hand, several vegetation indices, obtained by means of remote and proximal sensing have been developed, tested and improved along the last 40 years by researchers in order to estimate and compare many leaf and canopy properties. Normalized difference vegetation index (NDVI) is normally correlated with vegetative vigor (Broge and Leblanc, 2000), so this can be seen as another rapid means of obtaining spatial information for detailed soil and canopy mapping. Spectroradiometers, together with the development of radiative transfer models (Liang, 2004), have facilitated the study of some plant nutrients such as nitrogen, phosphorous and potassium.

The success of these technological innovations depends on advances in the state of knowledge about the decision support systems. At present, little is known about the nature, extent or stability of within-field variation in vineyard soils and whether it would be feasible to manage such variation in a site-specific way. The emergence of variable rate technology (VRT) for differential application of inputs (eg. fertilizers), makes site-specific management particularly important for closing the Precision Agriculture (PA) cycle.

The aim of this study was to evaluate the spatial and temporal patterns of phosphorus, potassium and $\mathrm{pH}$ at two times (2011 and 2013) in a vineyard and, consequently, to evaluate the potential for improving vineyard fertilizer management and $\mathrm{pH}$ correction. Simultaneously, the applicability of new tools $\left(\mathrm{EC}_{\mathrm{a}}\right.$ sensor and NDVI sensor) for monitoring spatial variability of soil or plant parameters in vineyard was evaluated.

\section{Material and Methods}

\subsection{Site characteristics}

The Casito vineyard, with an area of about 80 ha, divided in 23 plots and with diverse grape varieties, is located at the Pinheiros farm (Lat: $38^{\circ} 32^{\prime} 37.87^{\prime \prime} \mathrm{N}$, Long: 52 $2^{\circ}$ 11.00 "W, Datum WGS84) in the Alentejo region, Southern Portugal. The predominant soils are derived from gneiss and migmatite parent material and classified as "Haplic Luvisols" and "Stagnic Luvisols" (FAO, 2006). The "Haplic Luvisols" occur mainly in the slopes and the "Stagnic Luvisols" in the more flat areas.

The climate is temperate with typical Mediterranean characteristics. The summers are usually hot and dry, while the winters are cold and wet; the springs and autumns have mild and moderate temperature ranges. The average annual precipitation is $550 \mathrm{~mm}$, and the rainfall is concentrated mainly in wintertime. The average air temperature is $16^{\circ} \mathrm{C}$. The absolute maximum air temperature is $42^{\circ} \mathrm{C}$. The average absolute minimum air temperature is approximately $12{ }^{\circ} \mathrm{C}$ with an absolute minimum of -5 ${ }^{\circ} \mathrm{C}$. Daily sunlight hours are maximum in the 3 month period before harvest, and the total annual sunlight is approximately 3000 hours. The Casito vineyard is irrigated, usually at $75 \mathrm{~mm}$ per season but up to $100 \mathrm{~mm}$ in very hot, dry years and is maintained and improved by an annual homogeneous application of $150 \mathrm{~kg} \mathrm{ha}^{-1}$ of a ternary fertilizer "Foskamónio" 14-28-10 (N-P-K).

The topography of this particular vineyard (Figure 1) can be characterized as undulating, with altitudes varying from approximately $240 \mathrm{~m}$ to $260 \mathrm{~m}$, and with gentle slopes varying from $0 \%$ to $10 \%$. A topographic survey of the area was carried out using a real time kinematic GPS instrument (Trimble RTK - 5700 GNSS, manufactured by TRIMBLE, GmbH, Am Prime Parc 11, 65479 Raunheim, Germany). The elevation data were sampled in the field with an all-terrain vehicle (ATV) on paths $5 \mathrm{~m}$ apart. 


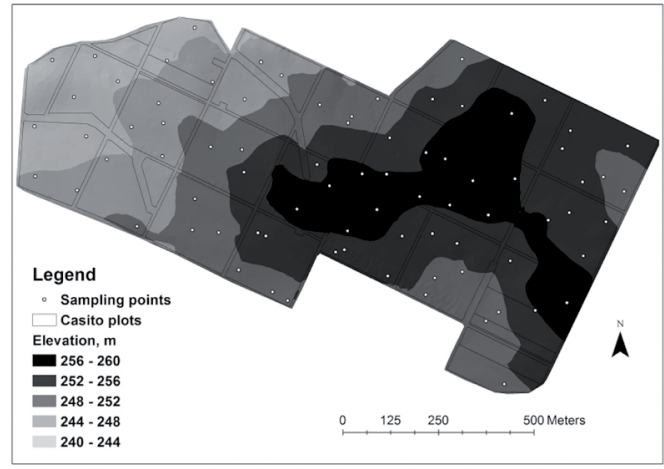

Figure 1. Sampling points and elevation map of the studied field.

\subsection{Soil sample collection and analysis}

Eighty composite soil samples were taken on March 2011 from the top layer $(0-0.30 \mathrm{~m})$, using a gouge auger and a hammer. Each composite sample comprised six sub-samples taken within a 3-m radius area of the georeferenced sampling point (Figure 1). Their location was based on a stratified random sampling scheme (Burrough and McDonnell, 1998) taking into consideration the relative field elevation. Their geographical coordinates were registered with the 5700 Trimble RTK GNSS survey-grade receiver. The soil samples were placed into plastic bags, air-dried and characterized in terms of $\mathrm{pH}, \mathrm{P}_{2} \mathrm{O}_{5}$ and $\mathrm{K}_{2} \mathrm{O}$ using the following methods; $\mathrm{pH}$ in 1:2.5 (soil: water) suspension, using the potentiometric method; extractable $\mathrm{P}_{2} \mathrm{O}_{5}$ and $\mathrm{K}_{2} \mathrm{O}$ with ammonium lactate and acetic acid, respectively (Egnér-Riehm method).

In March 2013, eighty composite soil samples were collected at the same georeferenced sampling points of 2011 and at the same depth and the soil was characterized in terms of texture (sand, silt and clay contents), $\mathrm{pH}$, organic matter, $\mathrm{P}_{2} \mathrm{O}_{5}$ and $\mathrm{K}_{2} \mathrm{O}$. The soil samples were analyzed for particle-size distribution using a sedimentographer (Sedigraph 5100, manufactured by Micromeritics), after passing the fine components through a $2 \mathrm{~mm}$ sieve. The $\mathrm{pH}, \mathrm{P}_{2} \mathrm{O}_{5}$ and $\mathrm{K}_{2} \mathrm{O}$ of the fine components $(<2 \mathrm{~mm}$ fraction) were determined using the above-mentioned methods, while organic matter content was established using dry combustion at $1300{ }^{\circ} \mathrm{C}$ in a Leco SC144DR elemental analyser (LECO Corporation, St. Joseph, Michigan, USA).

\subsection{Plant sample collection and analysis}

Eighty composite petiole samples were taken on May 2013 (in vine flowering state) at the same locations as the soil samples shown in Figure 1. These samples were placed into plastic bags and frozen until lab processing. Each petiole composite sample contained approximately 200 petioles collected within a $3 \mathrm{~m}$ radius from the central coordinate of each soil position. The plant petioles were analysed for $\mathrm{P}_{2} \mathrm{O}_{5}$ and $\mathrm{K}_{2} \mathrm{O}$ after dry ashing in a muffle furnace, respectively by colourimetry and by flame emission spectrophotometry. The guidelines for interpreting the results of the petiole analysis were adapted from Robinson et al., (1997) and Goldspink and Howes (2001).

\subsection{Apparent soil electrical conductivity survey}

A Veris 3150 contact-type sensor (Veris Technologies, Salina, KS, USA), equipped with a global positioning system (GPS) antenna was used to measure $\mathrm{EC}_{\mathrm{a}}$ in the 80 ha studied field in March 2013. The soil resistance sensor was pulled by a conventional tractor at an average speed of $5.5 \mathrm{~km} \mathrm{~h}^{-1}$, along different parallel transects, approximately $10 \mathrm{~m}$ apart. The unit was programmed to register measurements every second (about $1.5 \mathrm{~m}$ interval in the travel direction) and to generate two sets of topsoil data from 0 to $0.30 \mathrm{~m}$ and 0 to $0.90 \mathrm{~m}$ depths. In this work only the data from the $0-0.30 \mathrm{~m}$ soil layer were used for correlation with soil parameters since the soil samples were also collected from this layer. 


\subsection{Vegetation multispectral survey}

A commercial OptRx active crop sensor equipped with a Trimble GNSS GeoExplorer 6000 series model 88951 with sub-meter precision (Trimble: $\mathrm{GmbH}$, Am Prime Parc 11, 65479 Raunheim, Germany) was used to measure the multispectral bands of the 80-ha vineyard on May 2013. The OptRx crop sensor was assembled on a metallic frame, and mounted on an ATV at $0.5 \mathrm{~m}$ above vineyard vegetation and pulled along different parallel transects, approximately 10 $\mathrm{m}$ apart. This sensor, constructed by Ag Leader (2202 South River Side Drive Ames, IOWA 50010, USA), measures simultaneously three infrared bands: i) RED (670 $\mathrm{nm}$ with a range of $20 \mathrm{~nm}$ ); ii) RED EDGE (728 $\mathrm{nm}$ with a range of $16 \mathrm{~nm}$ ); and iii) NIR (775 $\mathrm{nm}$ with basically everything under $750 \mathrm{~nm}$ being filtered). With two of the previous spectral bands, NDVI vegetation index was calculated considering the following expression (Equation. 1):

$$
N D V I=\frac{N I R-R E D}{N I R+R E D}
$$

2.6. Classical statistics, geostatistical and regression analyses

Descriptive statistics including means, standard deviations (SD), coefficients of variation (CV), ranges and skewness values were determined for each dataset.

A grid-based Digital Elevation Model (DEM) surface was created using the linear interpolation based on a triangular irregular network (TIN) tool from ArcGIS 10.1 (ESRI, 2012) and converted into a raster DEM with $1 \mathrm{~m}$ resolution.

Ordinary kriging, which is referred in the literature as being the best unbiased estimator (Castrignanò and Buttafuoco, 2004), was used as the interpolation algorithm for soil and plant parameters. The surfaces previously obtained by geostatistical analyses were converted to a grid format with a $10 \mathrm{~m}$ resolution and developed in "Geostatistical analyst tool" and "Spatial analyst tool" of the ArcGIS 10.1 (ESRI, 2012). All measurements of ECa and NDVI were transferred to ArcGIS 10.1 (ESRI, 2012). To interpolate these data the IDW (inverse distance weighted) method was used, with a variable search radius considering of a minimum of 12 points and a $10 \mathrm{~m}$ by $10 \mathrm{~m}$ grid. According to Watson (1992) when the sampling density of a parameter is extremely high, which is the case of these two parameters, kriging interpolation is identical to the IDW method. Regression analysis was used to examine relationships of $\mathrm{EC}_{\mathrm{a}}$ ( 0 to $0.30 \mathrm{~m}$ depth) and NDVI data with elevation, soil and plant parameters. Correlation coefficients " $r$ " for the statistically significant regression relationships $(p<0.05)$ were then presented.

\subsection{Spatial variability analysis}

The spatial variability in soil parameters was calculated as the mean value $\left(\overline{y_{i}}\right)$ at the $i^{\text {th }}$ sampling point over the 2-year period of evaluation (2011 and 2013) according to the methodology suggested by Shi et al., (2002) and Xu et al., (2006) (Equation 2). The stability of soil parameters was determined by calculating the average coefficient of variation $(\overline{C V})$ for all sampling points over the years of evaluation (Shi et al., 2002; Xu et al., 2006). (Equation 2)

$$
\overline{y_{i}}=\frac{\sum_{t=1}^{n} y_{i_{t}}}{n}
$$

where $y_{i}$ is the soil parameter value at the sampling point $i$ at time $t$ and $n$ is the number of sampling years. 


\subsection{Temporal stability analysis}

The temporal stability of soil parameters was determined by calculating the coefficient of variation at each sampling point over the years of evaluation (Equation. 3) (Xu et al., 2006)

$$
C V_{i}=\frac{\left(\frac{n \sum_{t=1}^{t=n} y_{i_{i}}^{2}-\left(\sum_{t=1}^{t=n} y_{i_{i}}\right)^{2}}{n(n-1)}\right)^{0.5}}{\overline{y_{i}}} \times 100
$$

where $\mathrm{CV} i$ is the coefficient of variation over time at sampling point $i$.

The average temporal coefficient of variation $(\overline{C V})$ for each year for all sampling points was calculated as follows (Equation. 4) (Xu et al., 2006):

$$
\overline{C V}=\frac{\left(\sum_{i=1}^{\cdots} C V_{i}\right)}{m}
$$

where $m$ is the number of soil sampling points.

The annual $\overline{C V}$ for all sampling points was calculated to show the relative magnitudes of temporal variation for soil parameters; large values of $\overline{C V}$ indicate considerable temporal variation.

\subsection{Maps of management classes}

These data were combined into two maps that characterize the spatial variability and the temporal stability of soil parameters, recorded over the 2-year period. Although the two techniques described above quantify the spatial and temporal variation, they can be combined further into a single map of management classes, each with different characteristics which can be used for future decision making relative to site-specific management strategies for each field in subsequent seasons. The map of management classes shows areas that have consistently above or below reference values and characterize the temporal stability based on coefficient of variation (CV) of the parameters. These maps distinguish five different field areas in terms of their spatial and temporal characteristics: 1- high values (greater than field reference concentration) and stable; 2- high values and moderately stable; 3 - low values (smaller than field reference concentration) and stable; 4- low values (smaller than field reference concentration) and moderately stable; and 5- unstable (Xu et al., 2006). Each sampling point was represented by a coded value. The sampling points were classified by applying combinational logic statements to the spatial variation and temporal stability data sets, considering the following conditions: condition 1 (relative value) identifies whether the point is above or below the reference value for the parameter in question; condition 2 (temporal stability) identifies the stability of soil parameters at a particular point by comparing the $\mathrm{CV}$ to two arbitrary thresholds: stable if $\mathrm{CV}<$ $15 \%$; moderately stable if $15 \% \leq \mathrm{CV}<25 \%$; unstable if $\mathrm{CV} \geq 25 \%$ (Xu et al., 2006). A point was considered to belong to a particular class if both conditions were true, and it was then assigned an arbitrary class code shown in brackets.

\section{Results}

Table 1 presents the mean, standard deviation, coefficient of variation, range and skewness values of measured soil and plant parameters of the studied field in sampling years (2011 and 2013).

The average characteristics of the topsoil are: loamy sand to sand (clay $\sim 18 \%$ ); low levels of organic matter $($ mean $<1.0 \%)$; neutral $\mathrm{pH}($ mean $=6.8 \pm$ $0.3)$; relatively rich in potassium $\left(\mathrm{K}_{2} \mathrm{O}\right.$ mean $>100$ $\left.\mathrm{mg} \mathrm{kg}^{-1}\right)$; with average values of phosphorus $\left(\mathrm{P}_{2} \mathrm{O}_{5}\right.$ between $65-80 \mathrm{mg} \mathrm{kg}^{-1}$ ). 
Table 1. Mean, standard deviation, coefficient of variation, range and skewness values of soil and plant parameters in the studied field in sampling years (2011 and 2013).

\begin{tabular}{|c|c|c|c|c|}
\hline Parameter & Mean \pm SD & CV (\%) & Range & Skewness \\
\hline Soil2011 & & & & \\
\hline $\mathrm{P}_{2} \mathrm{O}_{5}, \mathrm{mg} \mathrm{kg}^{-1}$ & $79.08 \pm 129.60$ & 163.89 & {$[18.00-1062.00]$} & 0.58 \\
\hline $\mathrm{K}_{2} \mathrm{O}, \mathrm{mg} \mathrm{kg}^{-1}$ & $115.88 \pm 38.16$ & 32.93 & {$[58.00-202.00]$} & 0.54 \\
\hline $\mathrm{pH}$ & $6.65 \pm 0.33$ & 4.93 & {$[5.80-7.30]$} & -0.47 \\
\hline \multicolumn{5}{|l|}{ Soil2013 } \\
\hline $\mathrm{P}_{2} \mathrm{O}_{5}, \mathrm{mg} \mathrm{kg}^{-1}$ & $67.18 \pm 53.89$ & 80.22 & {$[13.00-398.00]$} & 0.68 \\
\hline $\mathrm{K}_{2} \mathrm{O}, \mathrm{mg} \mathrm{kg}^{-1}$ & $104.45 \pm 32.94$ & 31.53 & {$[44.00-198.00]$} & 0.50 \\
\hline $\mathrm{pH}$ & $6.85 \pm 0.30$ & 4.31 & {$[5.90-7.30]$} & -0.53 \\
\hline $\mathrm{OM}, \%$ & $0.91 \pm 0.19$ & 20.59 & {$[0.60-1.60]$} & 0.20 \\
\hline Sand, \% & $70.19 \pm 5.86$ & 8.35 & {$[56.43-81.95]$} & -0.32 \\
\hline Silt, \% & $11.59 \pm 2.41$ & 20.79 & {$[6.67-19.11]$} & 0.39 \\
\hline Clay, \% & $18.22 \pm 4.20$ & 23.04 & {$[9.01-29.37]$} & 0.26 \\
\hline $\mathrm{EC}_{\mathrm{a}}, \mathrm{mS} \mathrm{m}^{-1}$ & $4.41 \pm 2.65$ & 60.07 & {$[0.95-13.94]$} & 1.03 \\
\hline \multicolumn{5}{|l|}{ Plant2013 } \\
\hline $\mathrm{P}_{2} \mathrm{O}_{5}, \%$ & & 24.1 & {$[0.1$} & 0.64 \\
\hline $\mathrm{K}_{2} \mathrm{O}, \%$ & $3.07 \pm 0.82$ & 26.79 & {$[0.19-6.92]$} & -0.04 \\
\hline NDVI & $0.59 \pm 0.07$ & 12.00 & {$[0.18-0.82]$} & 0.06 \\
\hline
\end{tabular}

SD- Standard deviation; CV- Coefficient of variation; OM- Organic matter.

Table 2. shows the best variogram models obtained with the ordinary kriging interpolator for soil and plant parameters. Theoretical spherical and exponential quadratic models provided the best fit for all cases.

Table 2. Best variogram models obtained with the ordinary kriging interpolator for soil and plant parameters.

\begin{tabular}{lrrrrr}
\hline Parameter & Nugget effect & Partial sill & Range $(\mathrm{m})$ & Model & RMSSE \\
\hline Soil2011 & & & & & \\
$\mathrm{P}_{2} \mathrm{O}_{5}, \mathrm{mg} \mathrm{kg} \mathrm{k}^{-1}$ & 32.94 & 1076.42 & 206.48 & Spherical & 1.09 \\
$\mathrm{~K}_{2} \mathrm{O}, \mathrm{mg} \mathrm{kg}^{-1}$ & 0.00 & 1380.19 & 161.37 & Spherical & 0.93 \\
$\mathrm{pH}$ & 0.00 & 0.11 & 181.38 & Spherical & 0.93 \\
\hline $\mathrm{Soil2013}$ & & & & & \\
$\mathrm{P}_{2} \mathrm{O}_{5}, \mathrm{mg} \mathrm{kg}^{-1}$ & 0.00 & 1420.15 & 166.81 & Spherical & 1.11 \\
$\mathrm{~K}_{2} \mathrm{O}, \mathrm{mg} \mathrm{kg}^{-1}$ & 46.95 & 962.66 & 145.41 & Spherical & 0.92 \\
$\mathrm{pH}$ & 0.00 & 0.09 & 162.84 & Spherical & 0.93 \\
\hline Plant2013 & & & & & \\
$\mathrm{P}_{2} \mathrm{O}_{5}, \%$ & 0.00 & 0.01 & 132.53 & Exponential & 1.05 \\
$\mathrm{~K}_{2} \mathrm{O}, \%$ & 0.01 & 0.29 & 139.00 & Spherical & 1.14 \\
\hline
\end{tabular}

RMSSE: Root mean squared standardized error. 
Figures 2 and 3 show the spatial variability of soil $\mathrm{pH}$, $\mathrm{P}_{2} \mathrm{O}_{5}$ and $\mathrm{K}_{2} \mathrm{O}$ in 2011 and 2013, respectively.
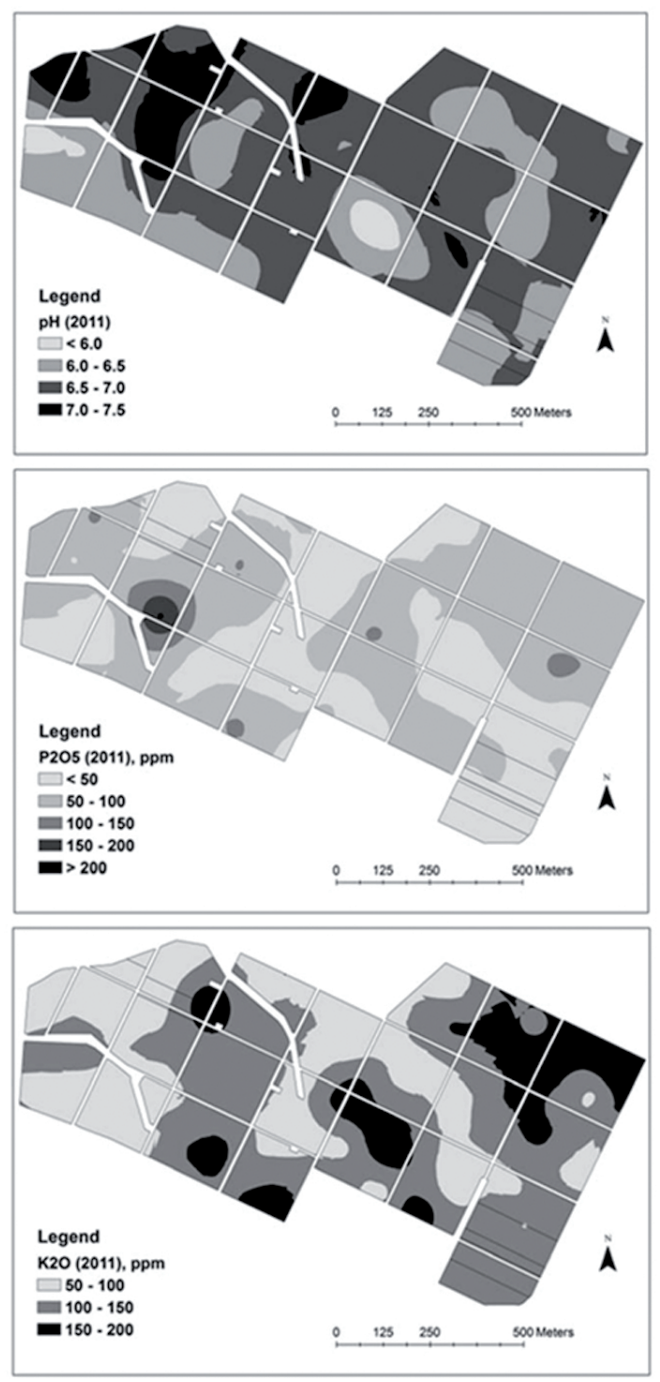

Figure 2. Spatial variability maps of the studied field in 2011: soil $\mathrm{pH}$ (top), phosphorus $\left(\mathrm{P}_{2} \mathrm{O}_{5}\right.$, middle) and potassium $\left(\mathrm{K}_{2} \mathrm{O}\right.$, bottom $)$ content.
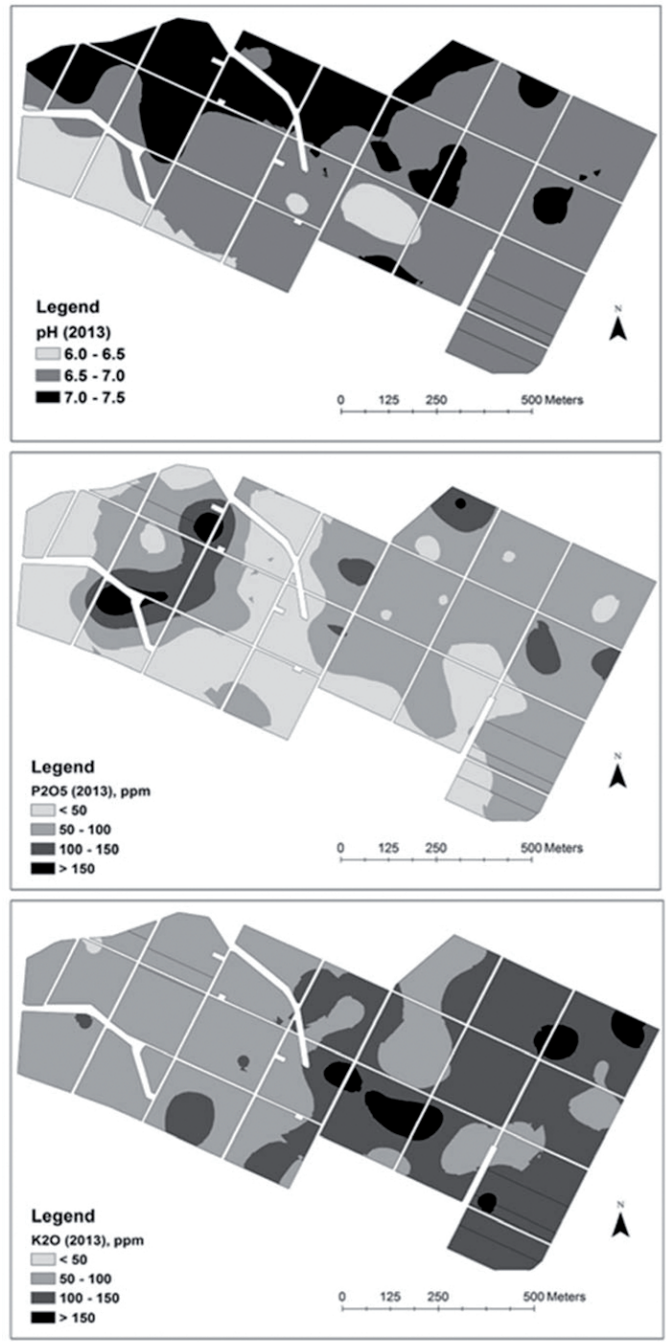

Figure 3. Spatial variability maps of the studied field in 2013: soil $\mathrm{pH}$ (top), phosphorus $\left(\mathrm{P}_{2} \mathrm{O}_{5}\right)$ (middle) and potassium $\left(\mathrm{K}_{2} \mathrm{O}\right)$ (bottom).

Phosphorus and potassium are involved in an array of processes in plants such as photosynthesis, respiration, energy generation, nucleic acid biosynthesis and constitute an integral component of several plant structures (Balemi and Negisho, 2012) 
Figure 4 shows the spatial variability of plant $\mathrm{P}_{2} \mathrm{O}_{5}$ and $\mathrm{K}_{2} \mathrm{O}$ content in May 2013 (vine flowering state).
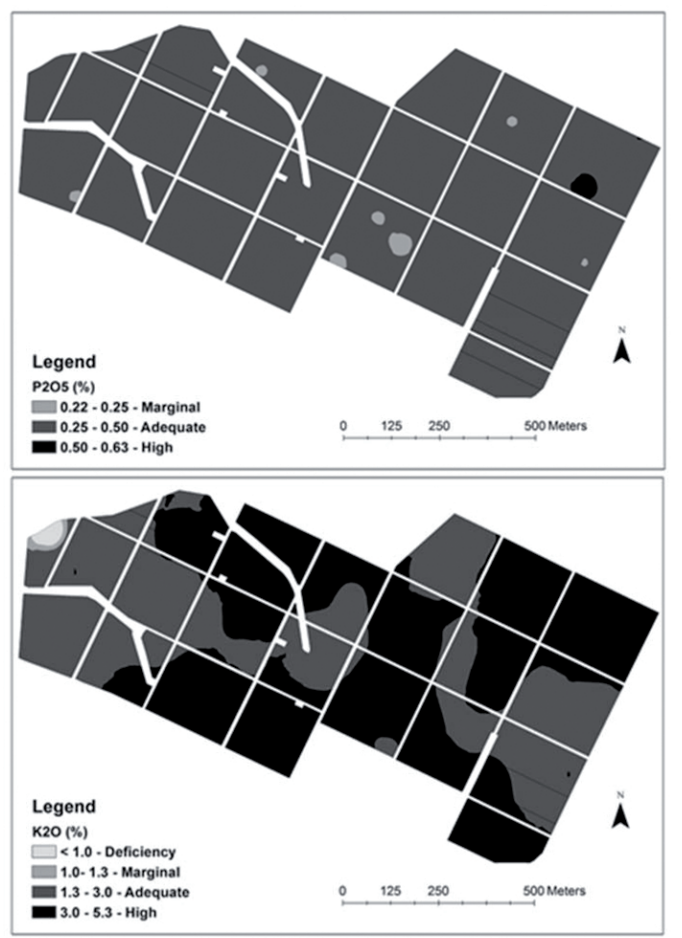

Figure 4. Spatial variability of plant phosphorus $\left(\mathrm{P}_{2} \mathrm{O}_{5}\right.$, top) and potassium $\left(\mathrm{K}_{2} \mathrm{O}\right.$, bottom) content in May 2013 (vine flowering state).

The variability shown by the measured soil parameters confirms the interest and the potential for a differentiated fertilization management. Figure 5 illustrates the management class maps of $\mathrm{pH}, \mathrm{P}_{2} \mathrm{O}_{5}$ and $\mathrm{K}_{2} \mathrm{O}$ organized by plots in the studied field.
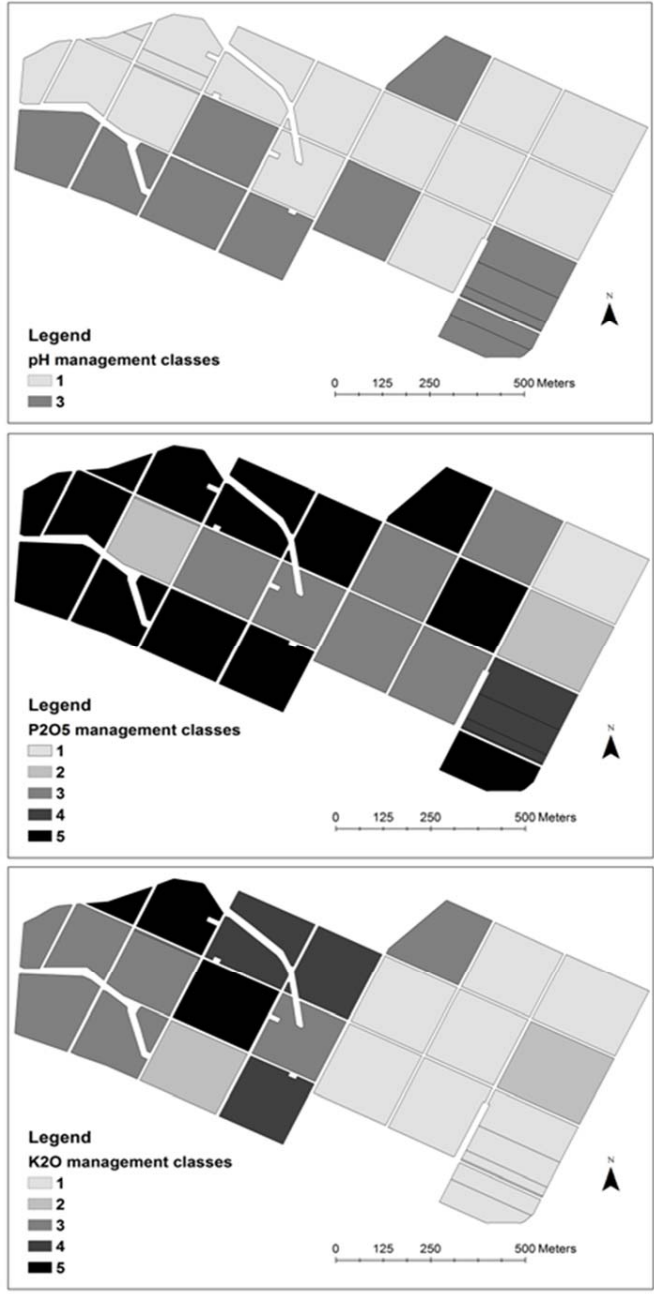

Figure 5. Management class maps of the studied field organized by existing field plots: $\mathrm{pH}$ (top), phosphorus $\left(\mathrm{P}_{2} \mathrm{O}_{5}\right.$, middle $)$ and potassium $\left(\mathrm{K}_{2} \mathrm{O}\right.$, bottom). 
Understanding relationships between sensor-based measurements and soil properties related to soil quality may help to develop soil management strategies to simplify the detailed soil and plant evaluation by conventional sampling (Mertens et al., 2008). Figure 6 shows the $\mathrm{EC}_{\mathrm{a}}(0-0.30 \mathrm{~m})$ and NDVI maps of the studied field in 2013 . This georeferenced information, obtained by soil electrical resistance and active crop sensors, respectively, show the important spatial variability of measured parameters in the studied field, especially the $\mathrm{EC}_{\mathrm{a}}$ (spatial $\mathrm{CV}=60 \%$ ), which confirms the spatial variability identified directly in the measured soil parameters.

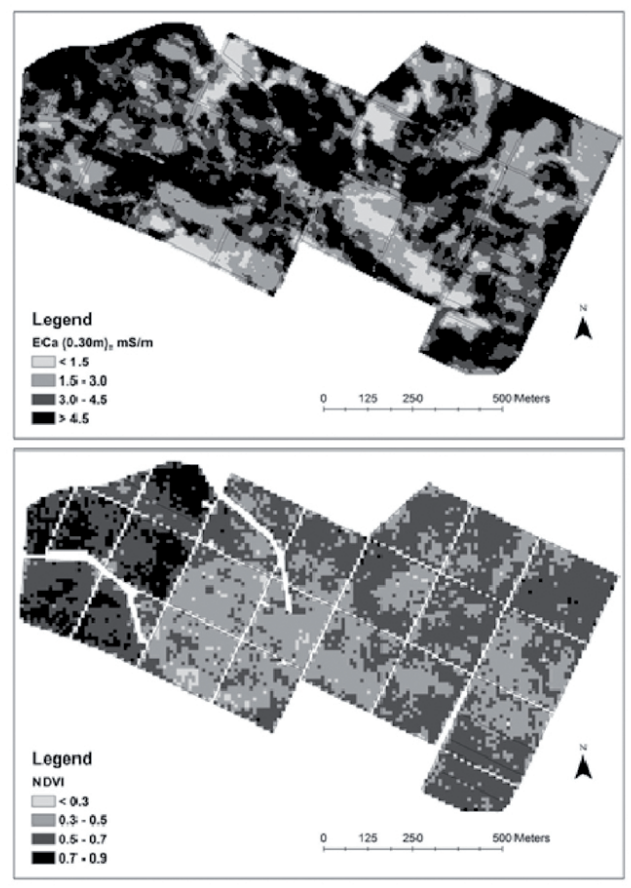

Figure 6. Maps of $\mathrm{EC}_{\mathrm{a}}$ (top, March 2013) and NDVI (bottom, May 2013) of the studied field.
According to André et al., (2012), the vegetation vigor (measured by NDVI) integrates the influence of all environmental factors, whereby vine NDVI can potentially be related to soil characteristics, such as electrical conductivity. In particular, high soil electrical conductivity values correspond to either high water, clay or nutrient contents, or a combination of these three (Corwin and Lesch, 2005). It would therefore be expected that a high electrical conductivity would correspond to a high NDVI, as these factors generally favour plant growth. However, this relationship is complex and factors such as soil compaction may have an opposite effect, namely, increasing $\mathrm{EC}_{\mathrm{a}}$ while limiting plant growth (André et al., 2012).

\section{Discussion}

\subsection{Soil and plant spatial variability}

Considering the classification proposed by Unamunzaga et al., (2014) based on the spatial CV, the spatial variation for some soil properties are high (>35\%), especially with regard to the $\mathrm{P} 2 \mathrm{O} 5(\mathrm{CV}>160 \%$ in 2011 and $80 \%$ in 2013) and $\mathrm{EC}_{\mathrm{a}}(\mathrm{CV}=60 \%)$. Potassium (CV 30\%), organic matter and texture (with spatial $\mathrm{CV}$ between 15 and 35\%) were moderately variable; $\mathrm{pH}$ is even less variable with a CV of less than $5 \%$. The undulating topography (approximately $20 \mathrm{~m}$ of difference in elevation between the highest and the lowest sampled points in the studied field, Figure 1), contributes decisively to spatial variability of the soil and crop characteristics.

In the case of plants, $\mathrm{P}_{2} \mathrm{O}_{5}$ and $\mathrm{K}_{2} \mathrm{O}$ were moderately variable $(\mathrm{CV} \sim 25 \%)$, while NDVI showed reduced variability $(\mathrm{CV}<15 \%)$. It is evident (Figure 4$)$ that 
plant $\mathrm{P}_{2} \mathrm{O}_{5}$ and $\mathrm{K}_{2} \mathrm{O}$ levels are, in almost generality of the study area, adequate or high, which do not reflect the measured soil concentrations. These results show the plant's ability to maintain adequate levels of nutrients, even if the soil presents relatively low concentrations. The nutrition of plants is predominantly controlled by the complex nutrients dynamics in the soil/rhizosphere-plant continuum (Shen et al., 2011). Rhizosphere is the interface between the plant and the soil, where plants acquire nutrients facilitated by biogeochemical processes (Larsen et al., 2015).

Under soil nutrient deficiency, plants can develop adaptive responses not only to facilitate efficient nutrient acquisition and translocation, but also to utilize stored nutrient more efficiently or limit nutrient consumption (Shen et al., 2011). An integrated understanding of the complex defence mechanisms of grapevine to edaphic stresses could lead to actions targeted at enhancing natural nutrient cycling, reequilibrating the nutritional status of plants and reducing dependence on mineral fertilizers in vineyard systems (Stevanato et al., 2014). These adaptations in root morphology and root physiology are a major grapevine characteristic resulting from its deep root structure, which allows it to absorb water and nutrients from great depths (Shen et al., 2011; Balemi and Negisho, 2012), particularly important in the case of phosphorus because of the relative immobility of this nutrient in the soil (Balemi and Negisho, 2012). Smart et al., (2006) observed that vine nutrition is favoured in the upper horizons with the lower layers contributing to the overall water supply.

\subsection{Management class maps}

Soil nutrient spatial variability and temporal stability are two conditions which may justify differential management and are the basis for spatially variable fertilization (Blackmore et al., 2003). The distribution and dynamics of nutrients in soil has a significant spatio-temporal variation (Shen et al., 2011). Recent research in precision viticulture has focused on the use of management zones, which are defined as subfield regions within which the effects on the crop of seasonal differences in weather, soil and management, are expected to be more or less uniform (Morari et al., 2009). For this purpose, it is often useful to define classes from a set of multivariate spatial data stored in a geographic information system.

The results show a high phosphorus $\left(\mathrm{P}_{2} \mathrm{O}_{5}\right)$ temporal $\mathrm{CV}$ ( $\overline{C V}=32.7 \pm 25.6 \%$; the unstable class represents more than $50 \%$ of the total area), which is unexpected, since the annual inputs are uniform throughout the parcel and the extraction by the crop is not significantly different from year to year. The complexity of soil phosphorus dynamics has been demonstrated by several studies. As a result of adsorption, precipitation and conversion to organic forms, only $10-30 \%$ of the applied mineral phosphate fertilizer can be recovered by the crop grown during the year of application (Balemi and Negisho, 2012). Despite the low potential for implementing site-specific management of phosphorus fertilizer, there is potential for implementing site-specific management of potassium fertilizer $(\overline{\mathrm{CV}}$ $=16.3 \pm 11.3 \%$; more than $90 \%$ of the total area is stable or moderately stable and $45 \%$ below the reference value) and $\mathrm{pH}$ correction ( $\overline{C V}=2.6 \pm 1.9 \% ; 100 \%$ stable and $41 \%$ below the reference value). 
In practical terms, the management class maps can help the wine grower undertake an intelligent sampling, fertilization and conditioning strategy for $\mathrm{pH}$, phosphorous and potassium. In the case of $\mathrm{pH}$, given its influence on the availability of other nutrients, it is recommended to confirm in future sampling campaigns any tendency for slightly acid $\mathrm{pH}$ values in the southwest area of the field (see Figures 2 and 3, top). In the case of phosphorus, there is a clear need to replenish $\mathrm{P}_{2} \mathrm{O}_{5}$ levels in approximately $80 \%$ of the field (see Figures 2 and 3, middle), however, the temporal instability (see Figure 5, middle) hinders the decision making of the wine grower and justifies extending the intensive sampling process at least for another campaign in order to confirm if the instability of the soil phosphorus concentration is maintained and, if so, to try to identify possible causes and any trends based on knowledge of the historic fertilizer management at this field. In the case of potassium,it is recommended to reduce the amounts of fertilizer, applying it as a function of the levels of this nutrient in the soil and to try to identify the causes for visible decline in the concentration of this nutrient below the values considered adequate (about $100 \mathrm{mg} \mathrm{kg}^{-1}$ ) in the western part of the field (see Figures 2 and 3, bottom).

\subsection{Relation of $E C_{a}$ and NDVI with elevation, soil and plant parameters}

Table 3 presents the correlation coefficients of $\mathrm{EC}_{\mathrm{a}}$ $(0-0.30 \mathrm{~m})$ and NDVI data with elevation, soil and plant parameters. The significant and negative values of the coefficients of correlation between ECa and elevation $(\mathrm{r}=-0.235 ; p<0.05)$ and between NDVI and elevation $(\mathrm{r}=-0.612 ; p<0.01)$ demonstrate the expected inverse relationship of these attributes, shown previously by Tarr et al., (2005). Serrano et al., (2010) also observed higher soil electrical conductivity in lower areas, where soil moisture levels tend to be naturally higher at the end of spring, in Mediterranean climates. Surface topography plays a significant role in influencing spatial $\mathrm{EC}_{\mathrm{a}}$ variation. Slope and topography will determine the level and location of water runoff and infiltration, which will influence the variations in water content and salinity. Areas with steeper slopes tend to have lower water content than depressional areas. The influence of surface topography on salinity distribution coincides with the influence of surface topography on water flow gradients, which result in salt transport (Corwin and Lesch, 2005). On the other hand, according to Fraisse et al., (2001), the vegetative vigour of plants (and, consequently NDVI) is strongly related to available water, so its variability can be approximately determined based on soil physical properties and topographic characteristics.

Table 3. Significant correlation coefficients of ECa $(0-0.30 \mathrm{~m})$ and NDVI data with elevation, soil and plant parameters

\begin{tabular}{lcc}
\hline Parameter & $\begin{array}{c}\mathrm{EC}_{\mathrm{a}}(0.30 \mathrm{~m}), \\
\mathrm{mS} \mathrm{m}^{-1}\end{array}$ & NDVI \\
\hline Elevation, $\mathrm{m}$ & $-0.235^{*}$ & $-0.612^{* *}$ \\
\hline Soil & & \\
Clay, \% & $0.574^{* *}$ & $\mathrm{~ns}$ \\
Silt, \% & $0.358^{*}$ & $\mathrm{~ns}$ \\
Sand, \% & $-0.558^{* *}$ & $\mathrm{~ns}$ \\
Organic matter, & $0.303^{*}$ & $\mathrm{~ns}$ \\
$\%$ & & \\
pH & $0.363^{*}$ & $0.244^{*}$ \\
$\mathrm{P}_{2} \mathrm{O}_{5}, \mathrm{mg} \mathrm{kg}^{-1}$ & $\mathrm{~ns}$ & $0.236^{*}$ \\
$\mathrm{~K}_{2} \mathrm{O}, \mathrm{mg} \mathrm{kg}^{-1}$ & $\mathrm{~ns}$ & $\mathrm{~ns}$ \\
\hline Plant $^{\mathrm{P}}$ & & \\
$\mathrm{P}_{2} \mathrm{O}_{5}, \mathrm{mg} \mathrm{kg}^{-1}$ & $\mathrm{~ns}$ & $\mathrm{~ns}$ \\
$\mathrm{~K}_{2} \mathrm{O}, \mathrm{mg} \mathrm{kg}^{-1}$ & $\mathrm{~ns}$ & $\mathrm{~ns}$ \\
\hline
\end{tabular}

** -Correlation significant at the 0.01 level; *-Correlation significant at the 0.05 level; ns-Correlation not significant; 
The point to emphasize is the weak, or the lack of correlation, between the $\mathrm{EC}_{\mathrm{a}}$ obtained by the Veris sensor and soil parameters and between NDVI and plant parameters. Apparent soil electrical conductivity measurements are often used directly for mapping variation patterns in agricultural soils, e.g. to guide soil sampling or to identify management zones (Rodríguez-Pérez et al., 2011). Modelling the relationships between soil variables and $\mathrm{EC}_{\mathrm{a}}$ is essential to assess and describe the spatial variability within a vineyard with sufficient precision. However, the task is not generally easy because $\mathrm{EC}_{\mathrm{a}}$ depends on many soil properties over different spatial scales, in a very complex way (Morari et al., 2009). In this study, the soil components that were most effectively mapped using ECa were the physical properties related to particle size distribution. Apparent soil electrical conductivity was significantly and negatively correlated with the coarser texture component (sand; $\mathrm{r}=-0.558 ; p<0.01$ ) and significantly and positively correlated with the finer ones (clay and silt; $\mathrm{r}=0.574 ; \mathrm{p}<0.01$ and $\mathrm{r}=0.358$; $p<0.05$, respectively). This relationship was also demonstrated by Morari et al., (2009) and RodríguezPérez et al., (2011). These soil physical parameters are of considerable importance for grape quality and nutrition (Rodríguez-Pérez et al., 2011). Generally the soil clay content is a soil fertility indicator as it affects structural and hydrological properties as well as nutrient availability and plant vegetative vigour. The significant correlation of $\mathrm{EC}_{\mathrm{a}}$ with soil organic matter observed in this work $(\mathrm{r}=0.303 ; p<0.05)$ is similiar to the results of several other studies (e.g., Corwin and Lesch, 2005). Also the significant correlation of ECa with $\mathrm{pH}(\mathrm{r}=0.363 ; p<0.05)$ is consistent with findings in previous studies and expected because it reflects the influence of salts on $\mathrm{EC}_{\mathrm{a}}$ readings (Serrano et al., 2010; Peralta and Costa, 2013).

For other chemical properties (such as phosphorus and potassium), the lack of correlation is in line with the findings of Rodríguez-Pérez et al., (2011) who reported no significant correlation between $\mathrm{EC}_{\mathrm{a}}$ and potassium. Also Peralta and Costa (2013) showed that $\mathrm{EC}_{\mathrm{a}}$ was not able to explain the variability in the concentration of nutrients of low electric charge, such as phosphorus and potassium.

Similarly to what happened with soil EC , phosphorus and potassium, also NDVI showed relatively poor and non-significant relationships with plant-based nutrients $\left(\mathrm{P}_{2} \mathrm{O}_{5}\right.$ and $\left.\mathrm{K}_{2} \mathrm{O}\right)$. This is an acceptable behaviour since the concentration of nutrients in the plants is adequate or high in all extension of the field (see Figure 4). It is, however, expected that in situations of plant nutrient deficiency, the plant vegetative vigour would be affected (e.g., the chlorosis of the leaves), a phenomenon detected by optical active sensors (Broge and Leblanc, 2000). Nutrient deficiency affects the physiology of different plant tissues, but normally leaf chlorosis is the most common symptom that can be observed (Bratasevec et al., 2013). This type of behaviour may imply that the best method to monitor vineyard nutrition, to identify nutritional deficiencies and to determine the need for nutrition adjustments would be based on the analysis of leaf nutrient concentration, because plants integrate all relevant soil conditions and express their nutritional deficiencies or toxicity in the vegetation. However, producers know that this method is relatively expensive, and they normally cannot obtain the spatial and temporal resolution required to optimize vineyard fertilization.

According to Homolová et al., (2013) it is possible to measure the concentration of phosphorus in plants using spectral empirical estimation models with average coefficients of determination of approximately 0.57. However, Pimstein et al., (2011) reported that no vegetation index specifically for plant $P$ estimation has been found. Therefore, a certain inconsistency exists among studies related to the use of spectroradiometers for this purpose and further research is necessary 
to solve some still-unclear aspects between spectral responses and plant nutrient concentration, namely, the low concentration of some nutrients in the leaves (e.g. mean $\mathrm{P}_{2} \mathrm{O}_{5}<0.5 \%$ ) and the real influence of canopy structure on spectral measurements (Balemi and Negisho, 2012). Additional works should evaluate and validate the active optical sensors in confirmed situations of plant deficiency.

In the past two decades, significant progress has been made in understanding soil, rhizosphere, and plant processes associated with soil nutrient transformation, mobilization and deficiency responses. However, many aspects of overall nutrient dynamics in the soil-rhizosphere-plant continuum are not thoroughly understood, including plant sensing of heterogeneous nutrient supply in soil (Shen et al., 2011). On the other hand, over the past 10 years, a number of new technologies based on electromagnetic properties and on multiespectral responses have emerged, whereas great progress has also been made in other existing technologies, such as infrared sensors, X-ray, nuclear magnetic resonance and magnetic resonant imaging (Ruiz-Altisent et al., 2010). These developments have opened new areas of research in agriculture as well as new applications for sensing crop quality (Ruiz-Altisent et al., 2010). It is expected that this situation will lead to the development of new field operational sensors, capable of detecting the concentration of nutrients in plants and allow the implementation of differential fertilizer management without the use of the complex and time-consuming process of spatial sampling.

\section{Conclusions}

This study, focusing on the evaluation of spatial and temporal variability of phosphorus and potassium in the soil and plant, shows the necessity of new paradigms in vineyard fertilizer management.
The conventional approach, based on composite soil samples, not taking into account the variability of soil fertility and plant nutrients concentration, is expensive and does not respond to the challenges offered today by variable rate technology in viticulture. The quantitative soil and plant analysis showed potential for implementing site-specific management. Given the importance of phosphorus and potassium for plants and their importance as a strategic resource, a better understanding of the nutrients dynamics in the soil-rhizosphere-plant continuum is necessary to guide the establishment of integrated nutrient management strategies.

Georeferenced information obtained by soil resistance and active crop sensors used in this study showed significant spatial variability in the studied field, which justified the interest in detailed evaluation of soil and plant parameters. However, the correlation of $\mathrm{EC}_{\mathrm{a}}$ with soil phosphorus and potassium and of NDVI with plant phosphorus and potassium is poor, which can be associated, respectively, with the capacity of the roots to explore soil layers deeper than the sampling depth (0.30-0.50 m) and the difficulty of the active optical sensor in detecting low concentrations of nutrients in plants unless these are visibly manifested under the form of leaf chlorosis.

These results show that vine nutrition management and optimization are rather complex and that currently, the challenge in terms of research, is to develop or adapt expedite, inexpensive and reliable tools, with acceptable spatial and temporal resolution for monitoring spatial variability of soil and plant nutrients.

\section{Acknowledgments}

This work was funded by FEDER Funds through the Operational Programme for Competitiveness Factors COMPETE and National Funds through FCT - Foundation for Science and Technology under the Strategic Project PEst-C/AGR/UI0115/2011 and under the FCT project - EXCL_AGR-TEC_0336_2012. 


\section{References}

André, F., van Leeuwen, C., Saussez, S., Van Durmen, R., Bogaert, P., Moghadas, D., Rességuier, L., Delvaux, B., Vereecken, H., Lambot, S. 2012. High-resolution imaging of a vineyard in south of France using ground-penetrating radar, electromagnetic induction and electrical resistivity tomography. J. Appl. Geophys. 78, 113-122.

Azcón-Aguilar, C., Barea, J.M. 2015. Nutrient cycling in the mycorrhizosphere. J. Soil Sci. Plant Nutr. 25(2), 372-396.

Balemi, T., Negisho, K. 2012. Management of soil phosphorous and plant adaptation mechanisms to phosphorus stress for sustainable crop production: a review. J. Soil Sci. Plant Nutr. 12(3), 547-561.

Blackmore, S., Godwin, R., Fountas, S. 2003. The analysis of spatial and temporal trends in yield map data over six years. Biosyst. Eng. 84, 455466.

Bratasevec, K., Sivilotti, P., Vodopivec, B.M. 2013. Soil and foliar fertilization affects mineral contents in Vitis vinifera L. cv. 'rebula' leaves. J. Soil Sci. Plant Nutr. 13(3), 650-663.

Broge, N. H., Leblanc, E. 2000. Comparing prediction power and stability of broadband and hyperspectral vegetation indices for estimation of green leaf area index and canopy chlorophyll density. Remote Sens. Environ. 76(2), 156-172.

Burrough, P.A., McDonnell, R.A. 1998. Principles of Geographical Information Systems. Oxford University Press, Oxford, UK.

Castrignanò, A., Buttafuoco, G. 2004. Geostatistical stochastic simulation of soil water content in a forested area of south Italy. Biosyst. Eng. 87 (2), 257-266.

Corwin, D., Lesch, S. 2005. Apparent soil electrical conductivity measurements in agriculture. Comput. Electron. Agr. 46, 11-43.
Doolittle, J.A., Brevik, E.C. 2014. The use of electromagnetic induction techniques in soils studies. Geoderma. 223-225, 33-45.

ESRI (Environmental Systems Research Institute) Inc. 2012. ArcView 10.19.3 GIS Geostatistical Analyst. Redlands: ESRI.

FAO (2006). World reference base for soil resources. World Soil Resources Reports №103. Food and Agriculture Organization of the United Nations, Rome, Italy.

Fraisse, C.W., Sudduth, K.A., Kitchen, N.R. 2001. Delineation of site-specific management zones by unsupervised classification of topographic attributes and soil electrical conductivity. T. ASAE. 44 (1), 155-166.

Goldspink, B.H., Howes, K.M. (Eds). 2001. Fertilisers for wine grapes. 3rd Edition. Department of Agriculture and Food Western Australia. Bulletin 4421.

Homolová, L., Malenovský, Z., Clevers, J.G.P.W., García-Santos, G., Schaepman, M.E. 2013. Review of optical-based remote sensing for plant trait mapping. Ecol. Complex. 15, 1-16.

Larsen, J., Jaramillo-López, P., Nájera-Rincon, M., Gonzaléz-Esquivel, C.E. 2015. Biotic interactions in the rhizosphere in relation to plant and soil nutrient dynamics. J. Soil Sci. Plant Nutr. 15(2), 449-463.

Liang, S. 2004. Quantitative Remote Sensing of Land Surfaces. John Wiley \& Sons, Inc., Hoboken, NJ, pp. 534.

Mertens, F.M., Paetzold, S., Welp, G. 2008. Spatial heterogeneity of soil properties and its mapping with apparent electrical conductivity. J. Plant Nutr. Soil Sc. 171(2), 146-154.

Moral, F., Terrón, J., da Silva, J.M. 2010. Delineation of management zones using mobile measurements of soil apparent electrical conductivity and multivariate geostatistical techniques. Soil Till. Res. 106, 335-343. 
Morari, F., Castrignanòb, A., Pagliarin, C. 2009. Application of multivariate geostatistics in delineating management zones within a gravelly vineyard using geo-electrical sensors. Comput. Electron. Agr. 68, 97-107.

Peralta, N. R., Costa, J. L. 2013. Delineation of management zones with soil apparent electrical conductivity to improve nutrient management. Comput. Electron. Agr. 99, 218-226.

Pimstein, A., Karnieli, A., Bansal, S.K., Bonfil, D.J. 2011. Exploring remotely sensed technologies for monitoring wheat potassium and phosphorus using field spectroscopy. Field Crop. Res. 121, 125-135.

Robinson, J.B., Treeby, M.T., Stephenson, R.A. 1997. Fruits, vines and nuts. In: D.J. Reuter and J. B. Robinson (Eds). Plant analysis an interpretation manual. CSIRO Publishing, Australia.

Rodríguez-Pérez, J., Plant, R., Lambert, J., Smart, D. 2011. Using apparent soil electrical conductivity (ECa) to characterize vineyard soils of high clay content. Precis. Agric. 12, 775-794.

Ruiz-Altisent, M., Ruiz-Garcia, L., Moreda, G.P., Lu, R., Hernandez-Sanchez, N., Correa, E.C., Diezma, B., Nicolaï, B., García-Ramos, J. 2010. Sensors for product characterization and quality of specialty crops, a review. Comput. Electron. Agr. 74(2), 176-194.

Serrano, J., Peça, J., Marques da Silva, J., Shahidian, S. 2010. Mapping soil and pasture variability with an electromagnetic induction sensor. Comput. Electron. Agr. 73, 7-16.

Serrano, J., Shahidian, S., Marques da Silva, J. 2014. Soil phosphorus retention in a Mediterranean pasture subjected to differential management. Eur. J. Soil Sci. 65, 562-572.
Shen, J., Yuan, L., Zhang, J., Li, H., Bai, Z., Chen, X., Zhang, W., Zhang, F. 2011. Phosphorus Dynamics: From Soil to Plant. Plant Physiol. 156(3), 997-1005.

Shi, Z., Wang, K., Bailey, J.S., Jordan, C., Higgins, A.H. 2002. Temporal changes in the spatial distributions of some soil properties on a temperate grassland site. Soil Use Manage. 18, 353-362.

Smart, D.R., Schwass, E., Lakso, A., Morano, L. 2006. Grapevine rooting patterns: a comprhensive analysis and a review. Am. J. Enol.Viticult. 57(1), 89-104.

Stevanato, P., Bertaggia, M., Stellin, F., Rizzi, V., Piffanelli, P., Angelini, E., Bertazzon, N., Fornasier, F. Squartini, A., Saccomani, M., Concheri, G. 2014. Soil biological anda biochemical traits linked to nutritional status in grapevine. J. Soil Sci. Plant Nutr. 14(2), 421-432.

Tarr, A., Moore, K., Bullock, D., Dixon, P. 2005. Improving map accuracy of soil variables using soil electrical conductivity as a covariate. Precis. Agric. $6,255-270$.

Unamunzaga, O., Besga, G., Castellón, A., Usón, M.A., Chéry, P., Gallejones, P., Aizpurua, A. 2014. Spatial and vertical analysis of soil properties in a Mediterranean vineyard soil. Soil Use Manage. 30(2), 285-296.

Watson, D. F. 1992. Contouring: a guide to the analysis and display of spatial data. Oxford, Pergamon, pp. 321 .

Xu, H.W., Wang, K., Bailey, J., Jordan, C., Withers, A. 2006. Temporal stability of sward dry matter and nitrogen yield patterns in a temperate grassland. Pedosphere. 16, 735-744. 